\title{
DOC biodegradation behavior along permafrost affected hydrological continuum
}

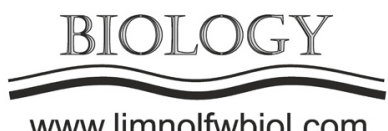

\author{
Payandi-Rolland D. ${ }^{1 *}$, Shirokova L.S. ${ }^{1,2}$, Tesfa M. ${ }^{1}$, Bénézeth P. ${ }^{1}$, Lim A. ${ }^{3}$, \\ Kuzmina D. ${ }^{3}$, Karlsson J. ${ }^{4}$, Giesler R. ${ }^{4}$, Pokrovsky O.S. ${ }^{1,2,3}$ \\ ${ }^{1}$ Geoscience and Environment Toulouse, GET-CNRS-IRD-OMP, University of Toulouse, 14 Avenue Edouard Belin, 31400 Toulouse, \\ France \\ ${ }^{2}$ Institute of Ecological Problems of the North, N. Laverov Federal Center for Integrated Arctic Research, Arkhangelsk, Russia \\ ${ }^{3}$ BIO-GEO-CLIM Laboratory, Tomsk State University, 35 Lenina Pr., Tomsk, Russia \\ ${ }^{4}$ Climate Impacts Research Centre (CIRC), Department of Ecology and Environmental Science, Umeå University, SE-981 07 Abisko, \\ Sweden
}

\begin{abstract}
In Arctic regions, water bodies are hot spots of dissolved organic carbon (DOC) biodegradation, and their well-known large heterogeneity in the permafrost affected area could lead to a misrepresentation of their importance in the carbon (C) cycle. In this study, the biodegradation potential of various water bodies from two hydrological continuums has been assessed via 15 days aerobic incubation of waters. Results show that biodegradability of waters increases along the continuum while the removal rate of DOC decreases as the consequence of a preferential biodegradation of low molecular weight organic acids (LMWOA). This preferential uptake leads to a relative accumulation of aromatic compounds in the end-members of the continuum. This suggests a shift in the dominantly used pools of DOC along the continuum: a rapidly consumed DOC pool at the beginning of the continuum and a more slowly consumed one at the end of the continuum.
\end{abstract}

Keywords: DOC removal rate, supra-permafrost water, river, organic acids, aromaticity

\section{Introduction}

Arctic regions contain high amount of organic carbon (OC) trapped in soils and wetlands permafrost. Undergoing climate warming accelerated the permafrost thaw and released previously trapped OC to aquatic ecosystems and C cycle. One of the main processes that can degrade OC in those regions is the biodegradation. Spatial heterogeneity such as water bodies encountered in those regions can influence the biodegradation of OC. The concept of 'hydrological continuum' (HC) includes the movement of water from sources (suprapermafrost waters) through intermediate (streams and lakes) and terminal reservoirs (large rivers). All steps of the HC can influence the biochemical properties and biodegradability of surface waters (Pokrovsky et al., 2011; Shirokova et al., 2013). This study aimed to quantify the magnitude and assess the governing factors of OC biodegradation potential along a HC of two discontinuous permafrost areas: western Siberia and northern Sweden.

\section{Material and methods}

Seven waters from supra-permafrost to rivers, of both studied sites HC have been used in a biodegradation experiment. Following the protocol of Vonk et al. (2015), filtrated waters have been incubated at $20^{\circ} \mathrm{C}$ for 2 weeks. DOC, LMWOA concentrations and optical properties ( $\mathrm{SUVA}_{254}$ and E2:E4 ratio) have been analyzed.

\section{Results and Discussion}

The unexpected increase in biodegradability of waters (which represents the \% of consumed OC) with the HC (0 to $20 \%$ ) is at odds with the generally assumed concept of preferential use of small and easily biodegradable OC molecules. This concept should have led to the inverse trend along the HC. Others studies of rivers and collapsing permafrost have higher biodegradable DOC, ranging from 10 to $40 \%$ (Wickland et al., 2012; Abbott et al., 2014). The decreasing trend of DOC removal rate with the HC $(1.03 \pm 0.2$ to 0.20 $\pm 0.1 \mathrm{mgC} \mathrm{L}^{-1} \mathrm{~d}^{-1}$ ) suggests that waters at the beginning of the HC contain rapidly processed DOC, while end-embers contain slowly processed DOC. The increase of $\mathrm{SUVA}_{254}$ with incubation time (14 to $58 \%$ ) indicates the relative accumulation of aromatic compounds. The increase of the E2:E4 ratio with time in waters at the beginning of the HC suggests a selective removal of

*Corresponding author.

E-mail address: dahedrey.payandi-rolland@get.omp.eu (D. P-R)

(C) Author(s) 2020. This work is distributed under the Creative Commons Attribution 4.0 License. 
LMW components, also observed in this study by the rapid uptake of LMWOA in supra-permafrost waters incubations. Conversely, this ratio decreases in the end-members of the $\mathrm{HC}$ and reflects humic-like aromatic components degradation (Hutchins et al., 2017).

\section{Conclusion}

This study highlights the high biodegradability of streams and rivers waters, and the rapid processing of OC at the beginning of the HC. It also shows the shift in the dominantly used pools of DOC along the continuum, with a rapidly consumed DOC pool at the beginning and a more slowly consumed one at the end of the HC. Most importantly it points out the importance of taking into account the large spatial heterogeneity of waters bodies in discontinuous permafrost areas to better understand the regional $\mathrm{C}$ cycle and its possible retro-actions.

\section{Acknowledgments}

Siberian fieldwork was supported by the 2018 campaign ('BIOCARSIB') of the international program INTERACT and by the Russian Fund for Basic grant no. 19-29-05209-mk. Sweden fieldwork was supported by the international project for mobility funded by the University Paul Sabatier (Toulouse 3, France) ('BioCarZA').

\section{References}

Abbott B.W., Larouche J.R., Jones J.B. et al. 2014. Elevated dissolved organic carbon biodegradability from thawing and collapsing permafrost: permafrost carbon biodegradability. Journal of Geophysical Research: Biogeosciences 119: 20492063. DOI: $10.1002 / 2014 J G 002678$

Hutchins R.H.S., Aukes P., Schiff S.L. et al. 2017. The optical, chemical, and molecular dissolved organic matter succession along a boreal soil-stream-river continuum. Journal of Geophysical Research: Biogeosciences 122: 28922908. DOI: 10.1002/2017JG004094

Pokrovsky O.S., Shirokova L.S., Kirpotin S.N. et al. 2011. Effect of permafrost thawing on organic carbon and trace element colloidal speciation in the thermokarst lakes of western Siberia. Biogeosciences 8: 565-583. DOI: 10.5194/ bg-8-565-2011

Shirokova L.S., Pokrovsky O.S., Kirpotin S.N. et al. 2013. Biogeochemistry of organic carbon, CO2, CH4, and trace elements in thermokarst water bodies in discontinuous permafrost zones of Western Siberia. Biogeochemistry 113: 573-593. DOI: 10.1007/s10533-012-9790-4

Vonk J., Tank S., Mann P. et al. 2015. Biodegradability of dissolved organic carbon in permafrost soils and aquatic systems: a meta-analysis. Biogeosciences (BG) 12: 6915-6930. DOI: $10.5194 /$ bg-12-6915-2015

Wickland K.P., Aiken G.R., Butler K. et al. 2012. Biodegradability of dissolved organic carbon in the Yukon River and its tributaries: seasonality and importance of inorganic nitrogen. Global Biogeochemical Cycles 26. DOI: 10.1029/2012GB004342 